\title{
Laju Tumbuh Umbi Tanaman Kentang Varietas Granola dan Supejohn di Dataran Medium dengan Pemulsaan
}

\author{
Growth Rate of Potato Tuber Cultivars Granola and Supejohn at Medium Altitude \\ Using Mulching Method
}

Johannes E.X. Rogi ${ }^{*}$, Hanny S.G. Kembuan ${ }^{1}$, dan Johan A. Rombang ${ }^{1}$

Diterima 15 Februari 2016/Disetujui 06 Juli 2016

\begin{abstract}
Research on growth rate of two cultivars of potato c.v. Granola and Supejohn at medium altitude using mulching methods was conducted at Paslaten village, Subdistrict of West Langowan, District of Minahasa, North Sulawesi. Research location was at medium altitude of $750 \mathrm{~m}$ above sea level. The objectives of this research were to determine growth rate of potato tuber grown at medium altitude and the most suitable mulch. The research was arranged in a randomized complete block design with two treatments and three replications. The first factor was potato cultivars (Granola and Supejohn) and second factor was mulching methods (no mulch, straw mulch and black silver plastic). Research result showed that straw mulch treatment increased growth rate of Granola and Supejohn cultivars $0.87 \mathrm{~g}_{\text {plant }}{ }^{-1}$ day $^{-1}$ and $0.73 \mathrm{~g}_{\text {plant }}{ }^{-1}$ day $^{-1}$, respectively while black silver plastic treatment only increased the growth rate of Granola and Supejohn cultivars $0.70 \mathrm{~g} \mathrm{plant}^{-1}$ day $^{-1}$ and $0.59 \mathrm{~g}_{\text {plant }}{ }^{-1} \mathrm{day}^{-1}$, respectively. The highest tuber dry weight was achieved by straw mulch. The best treatment was Granola grown in straw mulch. The lowest growth rate occurred at the mulch treatment which were $0.49 \mathrm{~g}_{\text {plant }}^{-1}$ day $^{-1}$ for Granola cultivar and $0.47 \mathrm{~g} \mathrm{plant}^{-1}$ day $^{-1}$ for Supejohn cultivar.
\end{abstract}

Keywords: black silver plastic mulch, dry weight, growth rate, potato, straw mulch

\begin{abstract}
ABSTRAK
Penelitian tentang laju tumbuh tanaman kentang dengan 2 (dua) varietas yaitu Granola dan Supejohn di dataran medium dengan menggunakan mulsa dilakukan di Desa Paslaten, Kecamatan Langowan Barat, Kabupaten Minahasa Provinsi Sulawesi Utara. Lokasi penelitian berada di dataran medium dengan elevasi $750 \mathrm{~m}$ di atas permukaan laut. Penelitian bertujuan untuk mendapatkan besarnya laju tumbuh umbi tanaman kentang yang dikembangkan di dataran medium dan jenis mulsa yang paling sesuai. Penelitian menggunakan rancangan acak kelompok dengan 2 (dua) faktor dan 3 (tiga) ulangan yaitu faktor I tanaman kentang (varietas Granola dan Supejohn) dan faktor II yaitu perlakuan mulsa (tanpa mulsa, mulsa jerami dan mulsa plastik hitam perak). Hasil penelitian menunjukkan bahwa perlakuan mulsa jerami meningkatkan laju tumbuh umbi pada varietas Granola sebesar $0.87 \mathrm{~g}_{\text {tanaman }}{ }^{-1}$ hari $^{-1}$ dan varietas Supejohn sebesar $0.73 \mathrm{~g}_{\text {tanaman }}{ }^{-1}$ hari $^{-1}$. Perlakuan mulsa plastik hitam perak meningkatkan laju tumbuh umbi pada varietas Granola sebesar $0.70 \mathrm{~g}$ $\operatorname{tanaman}^{-1}$ hari $^{-1}$ dan varietas Supejohn $0.59 \mathrm{~g} \operatorname{tanaman}^{-1}$ hari $^{-1}$. Bobot kering umbi tertinggi dicapai oleh mulsa jerami. Perlakuan terbaik ialah varietas Granola yang diberi mulsa jerami. Laju pertumbuhan terendah terdapat pada perlakuan tanpa mulsa sebesar $0.49 \mathrm{~g}^{-1}$ hari ${ }^{-1}$ untuk kultivar Granola dan $0.47 \mathrm{~g}^{-1}$ hari ${ }^{-1}$ untuk Supejohn.
\end{abstract}

Kata kunci: bobot kering, kentang, laju tumbuh, mulsa jerami, mulsa plastik hitam perak

\footnotetext{
${ }^{1}$ Program Studi Agronomi PPS, Universitas Sam Ratulangi. Jalan kampus Unsrat. Manado 95115 Indonesia. email: jrinorogi@gmail.com (*penulis korespondensi)
} 


\section{PENDAHULUAN}

Produksi kentang di Indonesia telah meningkat dengan pesat selama dekade terakhir data tahun 2011 produksi 955488 ton dan tahun 2015 mencapai 1219558 ton (Direktorat Jenderal Hortikultura, 2015) dan menjadikan Indonesia sebagai negara penghasil kentang terbesar di Asia Tenggara. Kentang termasuk komoditas sayuran penting dan berperan penting dalam mendukung perekonomian nasional, khususnya dalam peningkatan pendapatan dan kesejahteraan masyarakat. Hasil penelitian Bank Indonesia Tahun 2008 mendapatkan bahwa keuntungan petani kentang rata-rata $\mathrm{Rp} 30$ Juta. Di Indonesia pengembangan kentang banyak dilakukan di dataran tinggi ( $>1000 \mathrm{~m}$ di atas permukaan laut). Pengembangan kentang di dataran tinggi tersebut menghadapi banyak tantangan antara lain bersaing dengan komoditas hortikultura lainnya serta konversi lahan untuk peruntukan lainnya. Hal Ini mengakibatkan luas lahan untuk pengembangan kentang di dataran tinggi terus mengalami penyusutan dari tahun ke tahun. Data menunjukkan bahwa luas panen tanaman kentang tahun 2014 (76 291 Ha) dan 2015 (65 $709 \mathrm{Ha})$ mengalami penyusutan $10582 \mathrm{Ha}$ (Direktorat Jenderal Hortikultura, 2015). Untuk meningkatkan produksi, pencarian daerah pengembangan kentang yang lain seperti dataran medium (400-800 m dpl) dapat dijadikan solusi untuk memecahkan masalah penyusutan lahan di dataran tinggi. Pengembangan kentang di dataran medium masih menghadapi kendala seperti kurangnya varietas tanaman kentang yang sesuai dan adaptasi kentang terhadap perubahan lingkungan tumbuh. Upaya untuk menghadapi tantangan pengembangan kentang di dataran medium antara lain dapat dilakukan dengan pemuliaan varietas kentang yang toleran terhadap perubahan lingkungan di dataran medium dan memodifikasi lingkungan tumbuh tanaman kentang.

Varietas kentang Granola dan Supejohn merupakan varietas yang paling banyak dikembangkan di daerah Sulawesi Utara (Sambeka, 2012). Varietas Supejohn dan Granola jika dikembangkan di dataran tinggi secara morfologi mengeluarkan bunga (Oping, 2012), sedangkan varietas Granola tidak mengeluarkan bunga (Handayani et al., 2011).
Produksi kentang verietas Supejohn dan Granola dipengaruhi oleh ketinggian tempat (Mailangkay et al., 2012). Selanjutnya, hasil penelitian Mailangkay (2012) menunjukkan bahwa produksi umbi kentang tidak dipengaruhi oleh varietas tetapi oleh ketinggian tempat, yang berhubungan erat dengan keadaan iklim setempat seperti suhu, kelembaban tanah, curah hujan dan radiasi matahari. Dezfouli dan Herbert (1992), Pliska (2008) mendapatkan bahwa gangguan iklim dapat mengakibatkan luas daun yang lebih kecil sehingga terjadi penurunan produksi kentang hingga mencapai $20-30 \%$. Khan et al. (2011) mendapatkan faktor lain yang berpengaruh pada pertumbuhan tanaman kentang yang dapat dikontrol oleh petani yaitu varietas kentang, nutrisi dan pengendalian hama dan penyakit. Selain itu, kendala yang dihadapi pengembangan kentang di dataran medium adalah suhu tanah yang relatif lebih tinggi dibandingkan di dataran tinggi yang mengakibatkan gangguan bagi tanaman untuk berproduksi. Hasil penelitian Rykaczewka (2015) mendapatkan bahwa selain produksi mengalami hambatan, suhu yang tinggi menyebabkan tuberisasi sekunder dan cacat fisiologis umbi. Untuk mengatasi hal ini, pemakaian mulsa dapat dijadikan salah satu alternatif untuk mengatur suhu tanah agar sesuai untuk pertumbuhan kentang di dataran medium. Chang (1968) melaporkan bahwa suhu tanah optimal untuk pertumbuhan umbi kentang sekitar $17{ }^{\circ} \mathrm{C}$. Pemakaian mulsa menurunkan jumlah radiasi matahari yang diabsopsi tanah. Infiltrasi air, dan kehilangan air oleh evaporasi dapat ditekan sehingga air tanah lebih efisien pemanfataannya (Untung $e t$ al., 2009). Suharjo et al. (2010) mengatakan bahwa salah satu pendekatan untuk mengatasi masalah cekaman terhadap suhu tinggi adalah merakit teknologi budidaya tanaman kentang di dataran medium yang difokuskan kepada upaya menekan efek negatif cekaman kekeringan.

Dataran medium merupakan daerah pengembangan kentang yang baru di Sulawesi Utara sehingga diperlukan pengujian varietas yang cocok dikembangkan. Varietas yang cocok dikembangkan di dataran medium dapat dilihat dari laju tumbuh umbi masing-masing varietas tersebut yang dikombinasi dengan pemakaian mulsa, Tujuan penelitian ini untuk mendapatkan besarnya laju tumbuh umbi 
tanaman kentang yang dikembangkan di dataran medium dan jenis mulsa yang paling sesuai.

\section{METODE PENELITIAN}

Penelitian dilaksanakan di Desa Paslaten, Kecamatan Langowan Barat Kabupaten Minahasa pada Bulan Maret sampai Juni 2012. Lokasi penelitian berada di daerah dataran medium dengan elevasi $750 \mathrm{~m}$ dari permukaan laut. Luas petak percobaan $260 \mathrm{~cm}$ x $480 \mathrm{~cm}$ dengan jarak tanam $30 \mathrm{~cm} \times 50 \mathrm{~cm}$. Penelitian dilaksanakan menggunakan rancangan acak kelompok (RAK) faktorial berdasarkan arah matahari dengan dua faktor dan tiga ulangan, yaitu :

Faktor I = Varietas kentang G2

- V1 = Varietas Granola

- V2 = Varietas Supejohn

Faktor II = Perlakuan mulsa

- M0 = Tanpa Mulsa

- M1 = Mulsa jerami (ketebalan $3 \mathrm{~cm}$ )

- M2 = Mulsa plastik hitam perak

Pengukuran suhu tanah dan laju tumbuh linier umbi dilakukan sebagai berikut:

\section{Suhu Tanah}

Pengukuran suhu tanah dilakukan dengan menggunakan termometer tanah pada kedalaman $15 \mathrm{~cm}$ dari permukaan tanah dan waktu pengamatan dilakukan pada pagi pukul 06.00-07.00, siang 11.00-12.00 dan sore $17.00-18.00$.

\section{Laju Tumbuh Linear Umbi}

Pengambilan sampel dilakukan selang 14 hari sekali yang diambil dari petak destruktif (setiap pengambilan diambil 2 sampel tanaman).

Pengamatan bobot kering tanaman dengan mengeringkan tanaman 4 hari dengan panas matahari selama 2-3 hari di dalam oven pada suhu $70{ }^{0} \mathrm{C}$, sampai didapatkan bobot kering yang konstan.

Laju tumbuh dalam periode linear 14 harian mengambarkan laju penambahan bobot kering total tanaman per satuan luas lahan per satuan waktu rata-rata 14 harian. Menurut (Monteith, 1977) laju tumbuh linear dihitung dengan persamaan (1):

$\boldsymbol{C}_{m}=\boldsymbol{W}_{\boldsymbol{m}} \cdot \boldsymbol{t}_{m}{ }^{-1}$
Dimana:

$\mathrm{C}_{\mathrm{m}}=$ Laju tumbuh persatuan luas tanah persatuan waktu $\left(\mathrm{g} \cdot \mathrm{m}^{-1}\right.$ hari $\left.{ }^{-1}\right)$

$\mathrm{W}_{\mathrm{m}}=$ Bobot kering total dari satu satuan luas tanah $\left(\mathrm{g} . \mathrm{m}^{-2}\right)$

$\mathrm{t}_{\mathrm{m}}=$ Lama periode tumbuh linear (hari)

Analisis ini mengacu pada sifat pertumbuhan tanaman yang membentuk sigmoid. Pertumbuhan terbagi atas tiga fase: (1) fase lambat yang dimulai dari awal pertumbuhan tunas dari bibit akan muncul di atas permukaan tanah sampai tanaman memulai pertumbuhan linear yang disebut waktu hilang (lost time), (2) fase linear yaitu pertumbuhan tanaman berlangsung cepat secara relatif konstan, dan (3) fase menua yaitu pertumbuhan melambat akibat matinya bagianbagian tanaman (Paruntu, 1990). Secara operasional, peubah $\mathrm{C}_{\mathrm{m}}, \mathrm{t}_{\mathrm{m}}$, dan $\mathrm{t}_{0}$ diperoleh melalui pengukuran bobot kering tanaman per satuan waktu di atas kertas grafik yang kesemuanya dapat dilihat pada Gambar 1.

Gambar 1 dibuat atas dasar pengukuran bobot kering tanaman (y) per satuan waktu (minggu) (x). Kurva yang terbentuk ialah sigmoid yaitu pada awal pertumbuhan titik mendatar, kemudian naik tajam karena pertumbuhan yang cepat. Selanjutnya, titiktitik kembali mendatar karena mencapai fase penuaan. Apabila titik bagian yang menanjak dicarikan hubungan garisnya (menggunakan analisis regresi). Maka garis tersebut akan memotong sumbu $x$ di titik A. Jarak antara titik potong dengan titik awal (0) merupakan waktu hilang $\left(\mathrm{t}_{0}\right)$, yaitu waktu yang diperlukan tanaman untuk memulai pertumbuhan linear.

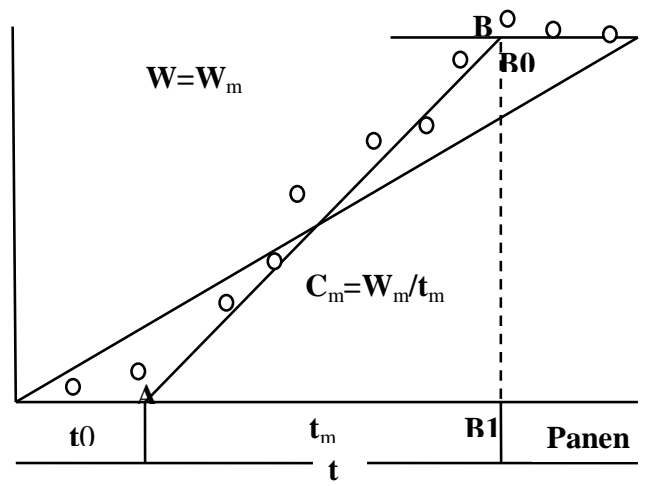

Gambar 1. Kurva pertumbuhan tanaman (Paruntu, 1990) 
Koefisien arah dari garis ialah laju tumbuh linear $\left(\mathrm{C}_{\mathrm{m}}\right)$. Rataan titik-titik pada fase menua merupakan bobot kering maksimum yang dicapai tanaman (W). Garis $\mathrm{W}_{\mathrm{m}}$ berpotongan dengan garis pertama pada titik B0 ke sumbu $x$ ialah B1. Jarak A-B1 menunjukkan lamanya pertumbuhan linear $\left(t_{m}\right)$. Hasil pengamatan dianalisis menggunakan sidik ragam dan dilanjutkan dengan uji beda nyata terkecil (BNT) $\alpha=5 \%$.

\section{HASIL DAN PEMBAHASAN}

\section{Suhu Tanah}

Berdasarkan hasil pengamatan terdapat perbedaan suhu tanah antara perlakuan tanpa mulsa, mulsa jerami, dan mulsa plastik hitam perak pada waktu pagi hari, siang hari, dan sore hari. Suhu pada waktu pagi hari dengan perlakuan mulsa plastik hitam perak lebih tinggi dibandingkan dengan tanpa perlakuan mulsa sebesar $1.48{ }^{\circ} \mathrm{C}$. Hal ini disebabkan curah hujan yang cukup tinggi selama pengamatan berlangsung baik dengan intensitas rendah maupun tinggi (Curah hujan selama penelitian berlangsung sebesar $859 \mathrm{~mm}$ dengan 71 hari hujan), sehingga uap air yang mengalami pemanasan pada saat terik disiang hari masih tersimpan di dalam permukaan mulsa plastik hitam perak. Suhu tanah mulsa jerami pada siang hari sebesar $24.41{ }^{0} \mathrm{C}$ atau lebih rendah $3.67{ }^{\circ} \mathrm{C}$ dibandingkan tanpa mulsa pada kedalaman 15 cm (Tabel 1).

Pengamatan yang dilakukan pada suhu tanah terhadap perlakuan mulsa menyebabkan suhu tanah berubah sesuai dengan aplikasi mulsa yang dilaksanakan, nantinya akan dapat dilihat dampak pada perkembangan tanaman kentang sesuai dengan variabel pengamatan yang ditentukan pada penelitian ini.

Tabel 1. Rataan suhu tanah $\left({ }^{0} \mathrm{C}\right)$ 0-98 hari setelah tanam (HST)

\begin{tabular}{lccc}
\hline \multicolumn{1}{c}{ Perlakuan } & Pagi & Siang & Sore \\
\hline Tanpa Mulsa & 22.66 & 28.08 & 28.48 \\
Mulsa Jerami & 22.94 & 24.41 & 26.03 \\
Mulsa Plastik & 24.14 & 26.45 & 28.93 \\
Hitam Perak & &
\end{tabular}

Keterangan: Waktu pagi : jam 06.00-07.00. Siang : Jam 11.00-12.00. Sore Jam 17.00-18.00.

\section{Suhu dan Kelembaban Udara}

Suhu udara di lokasi penelitian pagi hari rata-rata sebesar $19.37{ }^{\circ} \mathrm{C}$, siang hari sebesar $32.67{ }^{\circ} \mathrm{C}$, dan sore hari $29.79{ }^{\circ} \mathrm{C}$ dengan suhu maksimum $34.67{ }^{\circ} \mathrm{C}$ dan minimum $17.67{ }^{\circ} \mathrm{C}$, sedangkan kelembaban udara $86.25 \%$ pada pagi hari dan sore hari $86.13 \%$ (Tabel 2).

\section{Waktu Hilang Umbi Tanaman Kentang}

Interaksi antara varietas dan perlakuan mulsa terhadap peubah waktu hilang $\left(\mathrm{t}_{0}\right)$ pada bagian umbi tidak nyata. Data waktu hilang dapat dilihat pada Tabel 3. Waktu hilang $\left(\mathrm{t}_{0}\right)$ umbi berdasarkan analisis keragaman mempunyai pengaruh tunggal baik varietas maupun perlakuan mulsa. Varietas Granola menunjukkan waktu hilang yang lebih pendek (27.51 hari) dibandingkan dengan varietas Supejohn lebih panjang (28.53 hari), sedangkan pengaruh dengan perlakuan jerami terhadap waktu hilang lebih pendek dibandingkan perlakuan tanpa mulsa.

Tabel 2. Rataan suhu dan kelembaban udara 098 hari setelah tanam (HST)

\begin{tabular}{lcc}
\hline \multicolumn{1}{c}{ Waktu } & $\begin{array}{c}\text { Suhu } \\
\text { Udara }\left({ }^{0} \mathrm{C}\right)\end{array}$ & $\begin{array}{c}\text { Kelembaban } \\
\text { Udara }(\%)\end{array}$ \\
\hline Pagi & 19.37 & 86.25 \\
Siang & 32.67 & 41.60 \\
Sore & 29.79 & 86.13 \\
Maksimum & $34-36$ & \\
Minimum & $17-19$ & \\
\hline Keterangan: Waktu pagi jam 06.00-07.00. Siang hari: \\
\multicolumn{3}{c}{ Jam 11.00-12.00. Sore hari Jam 17.00- } \\
\multicolumn{3}{c}{ 18.00. Untuk suhu maksimum dan } \\
minimum pengambilan data 1x24 jam \\
dengan selang 1 minggu
\end{tabular}

Tabel 3. Rataan waktu hilang, umbi (hari)

\begin{tabular}{|c|c|c|c|c|}
\hline \multirow{5}{*}{ Varietas } & \multicolumn{4}{|c|}{ Perlakuan } \\
\hline & \multirow{4}{*}{$\begin{array}{l}\text { Tanpa } \\
\text { Mulsa }\end{array}$} & \multirow{4}{*}{$\begin{array}{l}\text { Mulsa } \\
\text { Jerami }\end{array}$} & \multicolumn{2}{|l|}{ Mulsa } \\
\hline & & & Plastik & \\
\hline & & & Hitam & Rataan \\
\hline & & & Perak & \\
\hline \multirow[b]{2}{*}{ Granola } & $27.59 \pm$ & $26.93 \pm$ & $28.00 \pm$ & \multirow{2}{*}{$27.51^{\mathrm{a}}$} \\
\hline & 0.10 & 0.27 & 0.23 & \\
\hline Supejohn & $\begin{array}{c}29.48 \pm \\
0.97\end{array}$ & $\begin{array}{c}27.68 \pm \\
0.45\end{array}$ & $\begin{array}{c}28.44 \pm \\
1.19\end{array}$ & $28.53^{\mathrm{b}}$ \\
\hline Rataan & $28.54^{\mathrm{b}}$ & $27.31^{\mathrm{a}}$ & $28.22^{\mathrm{ab}}$ & \\
\hline Keterangan: & Angka-an & gka yang & diikuti & eh huruf \\
\hline
\end{tabular}


Perlakuan mulsa plastik hitam perak mempunyai pengaruh yang sama dengan mulsa jerami maupun tanpa mulsa terhadap jumlah waktu hilang yaitu 28.22 hari.

\section{Periode Tumbuh Linear Umbi Tanaman Kentang}

Laju tumbuh linier umbi tanaman kentang dapat dilihat pada Tabel 4. Berdasarkan analisis varian laju tumbuh umbi menunjukkan pengaruh perlakuan berbeda nyata baik interaksi antara kedua varietas maupun dengan perlakuan mulsa. Perlakuan mulsa jerami memberikan dampak meningkatkan laju tumbuh linear umbi pada varietas Granola sebesar $0.87 \mathrm{~g}_{\text {tanaman }}{ }^{-1}$ hari $^{-1}$ bila dibandingkan dengan varietas Supejohn sebesar $0.73 \mathrm{~g} \mathrm{tanaman}^{-1}$ hari $^{-1}$.

Berdasarkan nilai rata-rata periode tumbuh linear umbi menunjukkan tidak berpengaruh nyata terhadap masing-masing perlakuan maupun interaksi di antara keduanya.

Tabel 4. Rataan periode tumbuh, umbi (hari)

\begin{tabular}{|c|c|c|c|c|}
\hline \multirow{5}{*}{ Varietas } & \multicolumn{4}{|c|}{ Perlakuan } \\
\hline & \multirow{4}{*}{$\begin{array}{l}\text { Tanpa } \\
\text { Mulsa }\end{array}$} & \multirow{4}{*}{$\begin{array}{l}\text { Mulsa } \\
\text { Jerami }\end{array}$} & Mulsa & \multirow{4}{*}{ Rataan } \\
\hline & & & Plastik & \\
\hline & & & Hitam & \\
\hline & & & Perak & \\
\hline \multirow[b]{2}{*}{ Granola } & $71.70 \pm$ & $71.39 \pm$ & $76.74 \pm$ & \multirow{2}{*}{73.28} \\
\hline & 1.03 & 1.47 & 2.87 & \\
\hline \multirow[t]{2}{*}{ Supejohn } & $78.94 \pm$ & $74.44 \pm$ & $77.01 \pm$ & \multirow{3}{*}{76.80} \\
\hline & 3.72 & 2.21 & 5.54 & \\
\hline Rataan & 75.32 & 72.91 & 76.87 & \\
\hline
\end{tabular}

Tabel 5. Rataan laju tumbuh umbi $\left(\mathrm{C}_{\mathrm{m}}\right)(\mathrm{g}$ $\operatorname{tanaman}^{-1}$ hari $^{-1}$ )

\begin{tabular}{|c|c|c|c|}
\hline \multirow[b]{2}{*}{ Varietas } & \multicolumn{3}{|c|}{ Perlakuan } \\
\hline & $\begin{array}{l}\text { Tanpa } \\
\text { Mulsa }\end{array}$ & $\begin{array}{l}\text { Mulsa } \\
\text { Jerami }\end{array}$ & $\begin{array}{l}\text { Mulsa } \\
\text { Plastik } \\
\text { Hitam } \\
\text { Perak }\end{array}$ \\
\hline Granola & $\begin{array}{c}0.49^{\mathrm{a}} \pm \\
0.01\end{array}$ & $\begin{array}{c}0.87^{\mathrm{d}} \pm \\
0.03\end{array}$ & $\begin{array}{c}0.70^{\mathrm{c}} \pm \\
0.02\end{array}$ \\
\hline Supejohn & $\begin{array}{c}0.47^{\mathrm{a}} \pm \\
0.07\end{array}$ & $\begin{array}{c}0.73^{\mathrm{c}} \pm \\
0.03\end{array}$ & $\begin{array}{c}0.59^{\mathrm{b}} \pm \\
0.04\end{array}$ \\
\hline Keterangan: & $\begin{array}{l}\text { Angka-angka } \\
\text { yang berbeda } \\
\text { adalah berbed }\end{array}$ & $\begin{array}{l}\text { ang diiku } \\
\text { ada kolo } \\
\text { yata pada }\end{array}$ & $\begin{array}{l}\text { oleh huruf } \\
\text { yang sama } \\
\text { n BNT 5\%. }\end{array}$ \\
\hline
\end{tabular}

Pengaruh perlakuan yang sama ditunjukan pula dengan peningkatan laju tumbuh linear umbi dengan perlakuan mulsa plastik hitam perak dikombinasikan dengan varietas Granola sebesar $0.70 \mathrm{~g}$ tanaman $^{-1}$ hari $^{-1}$ dibandingkan dengan laju tumbuh pada varietas Supejohn sebesar $0.59 \mathrm{~g}_{\text {tanaman }}^{-1}$ hari $^{-1}$. Laju tumbuh linear umbi terendah tampak pada perlakuan tanpa mulsa yang berpengaruh sama pada kedua varietas masing-masing, yang mana varietas granola sebesar $0.49 \mathrm{~g} \operatorname{tanaman}^{-1}$ hari $^{-1}$ dan varietas Supejohn $0.47 \mathrm{~g}_{\text {tanaman }}{ }^{-1}$ hari $^{-1}$.

\section{Bobot Kering Umbi}

Perlakuan mulsa berpengaruh terhadap bobot kering umbi tanaman kentang. Berdasarkan Tabel 6 perlakuan mulsa jerami meningkatkan bobot kering maksimum umbi kentang rata-rata sebesar $58.58 \mathrm{~g}$ dibandingkan dengan perlakuan mulsa plastik hitam perak $50.09 \mathrm{~g}$ maupun tanpa mulsa sebesar $36.62 \mathrm{~g}$.

Hasil penelitian ini menunjukkan bahwa terdapat pengaruh interaksi tanaman kentang varietas Granola dan Supejohn dengan perlakuan mulsa jerami, mulsa plastik hitam perak maupun tanpa mulsa menunjukkan berpengaruh nyata pada laju tumbuh linear umbi.

Laju tumbuh umbi merupakan hasil gambaran besarnya fotosintat yang dihasilkan tanaman per satuan waktu dan ruang. Hasil sidik ragam terhadap laju tumbuh linear umbi yang berbeda nyata sebagai akibat interaksi antar kedua varietas dan perlakuan mulsa dimana kombinasi antara varietas Granola dengan perlakuan mulsa jerami meningkatkan laju tumbuh linear umbi sebesar $0.87 \mathrm{~g}$ tanaman $^{-1}$ hari $^{-1}$ maupun varietas Supejohn sebesar $0.73 \mathrm{~g}_{\text {tanaman }^{-1}}$ hari $^{-1}$.

Tabel 6. Rataan Bobot Kering Maksimum Umbi (g)

\begin{tabular}{cccc}
\hline & \multicolumn{3}{c}{ Perlakuan } \\
\cline { 2 - 4 } Varietas & Tanpa & Mulsa & Pulsa \\
& Mulsa & Jerami & Hitam \\
& & & Perak \\
\hline \multirow{3}{*}{ Granola } & $35.34 \pm$ & $62.45 \pm$ & $54.29 \pm$ \\
& 0.58 & 2.41 & 0.57 \\
Supejohn & $37.89 \pm$ & $54.72 \pm$ & $45.90 \pm$ \\
& 6.35 & 3.78 & $5.88^{\mathrm{b}} \pm$ \\
& $36.61^{\mathrm{a}}$ & $58.58^{\mathrm{c}}$ & $50.09^{\mathrm{b}}$ \\
\hline
\end{tabular}


Sedangkan dengan mulsa plastik hitam perak sebesar $0.70 \mathrm{~g}$ tanaman $^{-1}$ hari $^{-1}$ untuk varietas Granola dan $0.59 \mathrm{~g}^{-1} \operatorname{tanaman}^{-1}$ hari $^{-1}$ untuk varietas Supejohn jika dibandingkan dengan perlakuan tanpa mulsa yang lebih rendah dengan kombinasi kedua varietas. Peningkatan laju tumbuh dengan perlakuan mulsa terutama mulsa jerami dapat dihubungkan dengan rataan suhu tanah (Tabel 1) terlihat bahwa perbedaan suhu tanah yang mencolok antara perlakuan mulsa jerami maupun mulsa plastik hitam perak dengan tanpa mulsa yang bersuhu tanah lebih tinggi berpengaruh pada kondisi suhu tanah yang optimal untuk perkembangan umbi kentang pada kedua varietas. Umbi cepat terbentuk disebabkan suhu tanah yang rendah pada pagi hari sekitar $22{ }^{\circ} \mathrm{C}$ dan siang hari $24{ }^{\circ} \mathrm{C}$ dengan perlakuan jerami dan mulsa plastik hitam perak sebesar $24{ }^{0} \mathrm{C}$ di pagi hari dan $26{ }^{\circ} \mathrm{C}$ pada siang hari, sedangkan untuk suhu udara yang tertera pada Tabel 2 bahwa suhu udara minimum sebesar $17-19^{\circ} \mathrm{C}$ dan maksimum 34$36{ }^{\circ} \mathrm{C}$. Walaupun belum termasuk suhu yang ideal, tetapi dapat menunjang untuk tunas cepat tumbuh. Suhu tanah yang rendah mempengaruhi pertumbuhan tunas karena dipengaruhi oleh hormon giberelin. Pengaruh hormon giberelin dan suhu serta interaksi diantara keduanya pada pertumbuhan tunas biji gandaria lebih cepat pada suhu rendah $4{ }^{0} \mathrm{C}$ dengan konsentrasi giberelin $0.4 \mathrm{ppm}$ dibandingkan suhu tinggi $37{ }^{0} \mathrm{C}$ dengan konsentrasi giberelin 0 ppm (Sinay, 2011).

Berdasarkan hasil sidik ragam untuk bobot kering maksimum umbi menunjukkan pengaruh terhadap pengaruh mulsa. Dari hasil tersebut, perlakuan mulsa jerami dan mulsa plastik hitam perak dapat meningkatkan bobot kering umbi kedua varietas yang tinggi dibandingkan dengan perlakuan tanpa mulsa akibat perubahan lingkungan mikro khususnya suhu tanah yang ditimbulkan. Hal ini sejalan dengan hasil penelitian Hamdani (2009) bahwa penggunaan mulsa jerami maupun mulsa plastik hitam perak memberikan bobot kering tertinggi tanaman kentang dibandingkan tanpa mulsa. Chozin et al. (2014) mendapatkan rata-rata bobot panen tertinggi pada tanaman tomat diperoleh pada perlakuan mulsa plastik hitam perak.

Suhu tinggi dapat menurunkan hasil umbi melalui dua hal, pertama rendahnya laju fotosintetis dalam penyediaan asimilat untuk seluruh pertumbuhan tanaman dan kedua mengurangi distribusi karbohidrat ke umbi sehingga hasilnya rendah. Suhu tinggi dan stres air mengurangi kualitas tanaman kentang yang mana penggunaan air meningkat dengan suhu yang lebih tinggi, sehingga mempercepat pengurangan kelembaban tanah (Johnstone, 2012). Selain pengaruh suhu tanah, pemakaian mulsa jerami juga dapat meningkatkan penetrasi oksigen (NHCP, 2011) dan meningkatkan KTK (Kapasitas Tukar Kation) (Harsono, 2012), sifat fisik tanah (Nur et al., 2011), menurunkan nilai bulk density, meningkatkan porositas tanah, dan mempertinggi bahan organik untuk tanaman nilam (Nasruddin et al., 2015) seperti terjadinya peningkatan nitrat (Tosic et al., 2014). Hal ini juga sesuai dengan penelitian Mayun (2007) dan Alwis et al. (2012) yang mengadakan penelitian pada umbi bawang merah dan nanas yang terjadi peningkatan produksi. Hasil penelitian Fahrurrozi et al. (1994), Hamdani (2009), Tegen et al. (2016) mendapatkan bahwa penggunaan mulsa jerami mengakibatkan penurunan suhu tanah siang hari pada kedalaman $5 \mathrm{~cm}$ sebesar $6{ }^{\circ} \mathrm{C}$ lebih rendah dibandingkan tanpa mulsa, sedangkan pada mulsa plastik hitam perak sebesar $3{ }^{\circ} \mathrm{C}$ dan memiliki kemampuan memantulkan 33\% cahaya matahari.

\section{KESIMPULAN}

Granola dapat dijadikan varietas kentang yang dikembangkan di dataran medium dengan pemakaian mulsa jerami karena memiliki laju tumbuh yang lebih tinggi yaitu $0.87 \mathrm{~g} \mathrm{tanaman}^{-1}$ hari $^{-1}$ dan bobot kering umbi sebesar $62.45 \mathrm{~g}$.

\section{DAFTAR PUSTAKA}

Alwis, A.J., H. Herath. 2012. Impact of mulching on soil moisture, plant growth and yield of Mauritius pineapple (Ananas comosus L. Merr). J. Food Agric. 2(1): 15-21.

Chang, J.H. 1968. Climate and Agriculture an Ecological Survey. Aldine Publ Comp. Chicago. 
Chozin, M.A., J.G. Kartika., R. Baharudin. 2014. Penggunaan kacang hias (Arachis pintoi) sebagai biomulsa pada budidaya tanaman tomat (Lycopersicon esculentum M.). J. Hort. Indonesia. 5(3): 168-174.

Bank Indonesia. 2008. Lending Model Budidaya Tanaman Kentang (Solanum tuberosum L.). Manado. 49 hal.

Dezfouli, A.H., S.J. Herbert. 1992. Intensifying plant density response of corn with artificial shade. J. Agron. 84: 547-551.

Direktorat Jenderal Hortikultura. 2015. Produksi sayuran di Indonesia 20112015. Kementerian Pertanian Republik Indonesia. Jakarta.

Fahrurrozi, K.A. Stewart. 1994. Effects of mulch optical properties on weed growth and development. HortScience. 29(6): 54.

Hamdani, S.J. 2009. Pengaruh jenis mulsa terhadap pertumbuhan dan hasil tiga kultivar kentang (Solanum tuberosum L.) yang ditanam di dataran medium. J Agron. Indonesia. 37(1): 14-20.

Handayani, T., E. Sofiari, Kusmana. 2011. Karakteristik morfologi klon kentang di dataran medium. Buletin Plasma Nutfah. 17(2): 116-121.

Harsono, P. 2012. Mulsa organik: pengaruhnya terhadap lingkungan mikro, sifat kimia tanah, dan keragaan cabai merah di tanah vertisol Sukoharjo pada musim kemarau. J. Hort. Indonesia 3(1): 35-41.

Johnstone, R. 2012. Managed Temperature in Potatoes to Improve Quality. Department of Agriculture and Food. Western Australian Agriculture.

Khan, A.A., M.S. Jilani, M.Q. Khan, M. Zubair. 2011. Effect of seasonal variation on tuber bulking rate of potato. J. Animal Plant Sci. 21(1): 3137.
Monteith, J.L. 1977. Climate. In P. Alvin and T.T Kozlowski. Ecophysiology of Tropical Crops. Academic Press. New York.

Mailangkay, B.H., J.M. Paulus, J.E.X. Rogi. 2012. Pertumbuhan dan produksi dua varietas kentang (Solanum tuberosum L.) pada dua ketinggian tempat. J. Eugenia. 8(2): 161-170.

Mayun, I. 2007. Efek mulsa jerami padi dan pupuk kandang sapi terhadap pertumbuhan dan hasil bawang merah di daerah pesisir. J. Agritrop. 26(1): 3340 .

Nasruddin, H. Harum. 2015. Kajian pemulsaan dalam mempengaruhi suhu tanah, sifat tanah dan pertumbuhan tanaman nilam. Pogostemon cablin Benth. J. Floratek. 10: 69-78.

NHCP. 2011. Mulching. Natural Resourses Conservation Service Practice Standart. Code $484-1$

Nur, K., A. Purwanto, D. Rosana. 2011. Peningkatan laju pertumbuhan dan produktivitas tanaman kentang (Solanum tuberosum L) melalui spesifikasi variabel fisis gelombang akustik pada pemupukan daun (melalui perlakuan variasi peak frekuensi). Universitas Negeri Yogyakarta. $14 \mathrm{Mei}$ 2011

Oping, H.W.M. 2012. Respon pertumbuhan dan hasil tanaman kentang (Solanum tuberosum L.) varietas Granola dan Supejhon terhadap pemberian pupuk organik cair. Tesis. Pascasarjana Universitas Sam Ratulangi. Manado. 52 hal.

Paruntu, J. 1990. Analisis tumbuh dan efisiensi penggunaan radiasi pada tanaman jagung I, pengaruh pemupukan nitrogen. Fakultas Pertanian, Universitas Sam Ratulangi, Manado.

Pliska, T. 2008. Potatoes and Climate Change. Swiss Agency for Development and 
Cooperation SDC. Swiss College of Agriculture SHL.

Rykaczewska, K. 2015. The effect of high temperature occurring in subsequent stages of plant development on potato yield and tuber physiological defects. American J. Potato Research. 92(3): 339-349.

Sambeka, F., S.D. Runtunuwu, J.E.X. Rogi. 2012. Efektifitas waktu pemberian dan konsentrasi paclobutrazol terhadap pertumbuhan dan hasil kentang (Solanum tuberosum L.) varietas Supejohn. J. Eugenia. 18(2): 126-133.

Sinay, H. 2011. Pengaruh giberelin dan temperatur terhadap pertumbuhan semai gandaria (Bouea macrophylla Grifftin.) Fakultas Keguruan dan Ilmu Pendidikan, Universitas Pattimura Ambon. 8(1): 15$22 \mathrm{Http} / / /$ www.unlam.ac.id/bioscientific.
Suharjo, U.K.J., C. Herison., Fahrurrozi. 2010. Keragaman tanaman kentang varietas Atlantik dan Granola di dataran medium (600 m dpl) Bengkulu pasca irradiasi sinar gamma. Akta Agrosia. 13(1): 82-88.

Tegen, H., Y. Dessalegn., W. Mohammed. 2016. Influence of mulching and varieties on growth and yield of tomato under polyhouse. J. Hort. Forestry. 8(1): 1-11.

Tosic, I., Z. Ilin, I. Maksinovic, S. Pavlovic. 2014. The effect of plant mulching and covering on the lettuce yield and nitrate content (Lactuca sativa L.). Afr. J. Agric. Research. 9(23): 1774-1777.

Untung, S., V. Krestiani. 2009. Studi pemulsaan dan dosis NPK pada hasil buah melon (Cucumis melo.L). J. Sains Teknol. 2(2): 1-7. 